This item was submitted to Loughborough's Research Repository by the author.

Items in Figshare are protected by copyright, with all rights reserved, unless otherwise indicated.

\title{
Stimulating whole saliva affects the response of antimicrobial proteins to exercise
}

PLEASE CITE THE PUBLISHED VERSION

http://dx.doi.org/10.1111/sms.12056

\section{PUBLISHER}

John Wiley \& Sons Ltd (@ 2013 John Wiley \& Sons A/S)

VERSION

AM (Accepted Manuscript)

\section{PUBLISHER STATEMENT}

This work is made available according to the conditions of the Creative Commons Attribution-NonCommercialNoDerivatives 4.0 International (CC BY-NC-ND 4.0) licence. Full details of this licence are available at: https://creativecommons.org/licenses/by-nc-nd/4.0/

\section{LICENCE}

CC BY-NC-ND 4.0

\section{REPOSITORY RECORD}

Allgrove, Judith E., Marta Oliveira, and Michael Gleeson. 2019. "Stimulating Whole Saliva Affects the Response of Antimicrobial Proteins to Exercise". figshare. https://hdl.handle.net/2134/17087. 
1 Stimulating whole saliva affects the response of antimicrobial proteins to exercise

2

3 Allgrove, Judith E. ${ }^{1,2}$, Oliveira, Marta. ${ }^{2}$ and Gleeson, Michael. ${ }^{2}$

4

$5 \quad{ }^{1}$ School of Life Sciences, Kingston University London, UK

$6 \quad{ }^{2}$ School of Sport, Exercise and Health Sciences, Loughborough University, UK

7

8 Corresponding author:

9 Dr Judith Allgrove

10 School of Life Sciences

11 Kingston University

12 London

13 KT1 2EE

14 Telephone: +442084172582

15 Fax: +442085477562

16 Email: judithallgrove@hotmail.co.uk

17

18 Running head: stimulated saliva flow, exercise and AMPs

19

20

21

22

23 Abstract 
1 This study investigated the salivary secretion rates of antimicrobial proteins in

2 response to prolonged, exhaustive exercise in both stimulated and unstimulated saliva

3 flow sample methods. Twenty four trained men cycled for $2.5 \mathrm{~h}$ at $60 \% \dot{\mathrm{VO}}_{2 \max }$ and

4 then to exhaustion at $75 \% \quad \dot{\mathrm{V}}{ }_{2 \max }$. Timed collections of whole saliva were made

5 before exercise, mid-exercise, at the end of the moderate exercise bout and post

6 exhaustive exercise. After each unstimulated (UNSTIM) collection a stimulated

7 sample (STIM) was collected following chewing flavoured gum for one minute.

8 Saliva was analysed for lysozyme, $\alpha$-amylase and salivary immunoglobulin A (s-

9 IgA), and secretion rates were calculated. Saliva flow was $156 \%$ higher in STIM

10 compared with UNSTIM $(\mathrm{P}<0.001)$ and decreased with exercise in STIM only

$11(\mathrm{P}<0.001)$. Exercise increased lysozyme and $\alpha$-amylase levels and secretion rates

12 were $144 \%$ higher and $152 \%$ higher in STIM compared with UNSTIM for lysozyme

13 and $\alpha$-amylase, respectively (all $\mathrm{P}<0.001)$. S-IgA concentration $(\mathrm{P}<0.05)$ and

14 secretion rate $(\mathrm{P}<0.001)$ increased with exercise but were both lower in STIM

15 compared with UNSTIM $(\mathrm{P}<0.001)$. In conclusion, a stimulated saliva flow collection

16 during exercise by chewing flavoured gum increased the quantity of saliva and the

17 secretion of lysozyme and $\alpha$-amylase, but had a limited impact on the secretion of s-

$18 \quad \operatorname{Ig} \mathrm{A}$.

19

20 Keywords: cycling, lysozyme, $\alpha$-amylase, immunogloblulin A, chewing 


\section{Introduction}

2 Saliva is a clear, slightly acidic mucoserous exocrine secretion consisting of inorganic

3 and organic compounds of usually more than $99 \%$ water. Saliva secretions play an

4 important role in maintaining the integrity of oral health via a mechanical washing

5 effect and through the secretion of antimicrobial proteins. These proteins constitute

6 the first line of defence against infectious agents and include both innate (lysozyme,

$7 \quad \alpha$-amylase) and adaptive (immunoglobulin A) immune components (Humphrey and

8 Williamson, 2001). The secretion of saliva into the mouth originates from three pairs

9 of major salivary glands; the submandibular glands contribute $\sim 65 \%$ of total

10 unstimulated whole saliva secretion, the parotid glands contribute $\sim 20 \%$, the

11 sublingual glands contribute $7-8 \%$ and the numerous minor salivary glands contribute

12 less than 10\% (Pedersen et al., 2002). The average daily flow of whole saliva varies

13 between 1 and 1.5 L (Humphrey and Williamson, 2001).

15 Saliva secretion is under strong autonomic neuronal control and thus regulated by

16 parasympathetic and sympathetic nerve fibres that are the effector arms of reflexes

17 activated predominantly by taste and chewing (Humphrey and Williamson, 2001).

18 Generally, when sympathetic stimulation dominates (via noradrenaline) the secretions

19 are high in protein content (e.g. $\alpha$-amylase), whereas secretions with a high fluid

20 output occur in response to parasympathetic stimulation (Chicharro et al., 1998).

21 However, parasympathetic stimulation can also affect salivary protein secretion, and

22 protein secretion of some glands such as the sublingual and some of the minor glands,

23 may even be entirely under parasympathetic control (Teeuw et al., 2004).

24 Furthermore, sympathetic stimulation also causes some stimulation of the saliva flow 
1 rate (Garrett, 1987), thus, rather than acting antagonistically, it could be argued that

2 the two branches of the autonomic nervous system may exert relatively independent

3 effects in which the activity of one branch may synergistically augment the other

4 (Bosch et al., 2002). Other factors known to influence saliva secretion include psychic

5 factors, nutrition, hydration status, medication, local or systemic diseases and physical

6 stress (Humphrey and Williamson, 2001), where significant reductions in the flow

7 rate and changes in the antimicrobial proteins have been observed. For example,

8 reductions in salivary immunoglobulin $\mathrm{A}(\mathrm{s}-\operatorname{Ig} \mathrm{A})$ levels have often been reported

9 following strenuous exercise (Tomasi et al., 1982; Mackinnon et al., 1989; Nehlsen-

10 Cannaralla et al., 2000; Nieman et al., 2002). However, other studies report increases

11 (Blannin et al., 1998; Walsh et al., 2004; Li and Gleeson, 2004; Sari-Sarraf et al., 12 2007; Allgrove et al., 2008; Allgrove et al., 2009; Costa et al., 2012) or no change

13 (McDowell et al., 1991; Walsh et al., 1999). $\alpha$-amylase (Li and Gleeson, 2004;

14 Allgrove et al., 2008) and lysozyme (Allgrove et al., 2008; West et al., 2010; Costa et 15 al., 2012) typically increase with exercise, although one study reported a significant 16 reduction in lysozyme levels post-exercise (Davison \& Diment, 2010) and in another 17 reductions were observed following a dehydration protocol (Fortes et al., 2012).

18 Changes in salivary antimicrobial proteins have been linked to the susceptibility of 19 upper respiratory symptoms in a variety of athletic/exercising populations (Gleeson et 20 al., 1999; Klentrou et al., 2002; Neville et al., 2008; Nieman et al., 2002; Fahlman \& 21 Engels, 2005; Cunniffe et al., 2011).

23 Athletes often consume both food items and beverages during exercise. It has been 24 shown that chewing can increase the flow rate by 3-fold compared with unstimulated 25 saliva secretion (Hector and Linden, 1987), and this has also been shown to increase 
1 the secretion of certain salivary proteins, including s-IgA probably via increased

2 epithelial cell trancytosis (Proctor and Carpenter, 2001). Similar increases were also

3 found in the secretion rates of total protein and $\alpha$-amylase (Proctor and Carpenter,

4 2001). Furthermore, saliva flow rate and protein concentration is increased in

5 response to gustatory stimulation (Proctor and Carpenter, 2007), with acid and sweet

6 taste stimuli providing the greatest response (Humphrey and Williamson, 2001).

7 Given that exercise and stimulated salivary flow can independently affect

8 antimicrobial proteins, it is possible that stimulating salivary flow during exercise

9 may potentially affect the salivary antimicrobial response, and represent mechanisms

10 by which resistance to oral infection may be altered. Therefore, the aims of the study

11 were to investigate the influence of stimulated saliva flow on salivary antimicrobial

12 proteins by chewing flavoured gum during prolonged exhaustive cycling. It was

13 hypothesised that stimulating saliva flow by chewing would acutely enhance

14 antimicrobial protein secretion during exercise.

15

16 Materials and methods

17 Participants

18 Following university ethical approval 24 trained male volunteers (mean \pm SD: age 23

$19 \pm 5 \mathrm{yr}$; height $1.79 \pm 0.07 \mathrm{~m}$; body mass $73.8 \pm 8.1 \mathrm{~kg} ; \dot{\mathrm{V}}{ }_{2 \max } 56.6 \pm 4.7 \mathrm{~mL} . \mathrm{kg}^{-}$

$20{ }^{1} \cdot \mathrm{min}^{-1}$ ) with cycling as one of their main sports, volunteered to participate in the

21 study. Participants completed a health questionnaire to report any symptoms of

22 infection or illness in the 12 weeks prior to commencing the study and were informed

23 of the aims and procedures before providing written informed consent. Participants 
1 were included if they were healthy endurance-trained male volunteers between the ages of 18-35 yr of age. Participants representing one or more of the following criteria

3 were excluded from the study: smoking or use of any medication or dietary

4 supplements or suffering from any known chronic disease.

\section{Preliminary measurements}

7 At least 2 weeks prior to the main trial participants performed an incremental test to

8 volitional exhaustion on an electronically braked cycle ergometer (Lode Excalibur,

9 Groningen, Netherlands) to determine their maximal oxygen uptake ( $\left.\dot{\mathrm{V}}{ }_{2 \max }\right)$.

10 Following a 3-min warm-up, participants began cycling at $95 \mathrm{~W}$ with increments of

$1135 \mathrm{~W}$ every $3 \mathrm{~min}$ with verbal encouragement was provided to each participant to

12 ensure maximal effort. Samples of expired gas were collected in Douglas bags

13 (Harvard Apparatus, Edenbridge, UK) during the third minute of each work rate

14 increment and ratings of perceived exertion (RPE) using the Borg scale were recorded

15 and heart rate (HR) was measured continuously using short-range radio telemetry

16 (Polar Beat, Polar Electro Oy, Kempele, Finland). An oxygen/carbon dioxide analyser

17 (Servomex 1400, Crowbridge, UK) was used along with a dry gas meter (Harvard

18 Apparatus, Edenbridge, UK) for the determination of oxygen uptake ( $\left.\mathrm{V}_{2}\right)$. Criteria

19 for attaining $\dot{\mathrm{V}} \mathrm{O}_{2 \max }$ included the participants reaching volitional exhaustion and a

20 heart rate within 10 beats/min of $\mathrm{HR}_{\max }$. From the $\dot{\mathrm{V}} \mathrm{O}_{2}$ work rate relationship, the

21 work rates equivalent to $60 \%$ and $75 \% \quad \dot{\mathrm{V}} \mathrm{O}_{2 \max }$ for each participant were interpolated.

23 Participants then completed a familiarisation ride. This ensured the subjects were able 24 to cope physically with the demands of the test, and for them to practice the saliva 
1 collection procedure. It also allowed saliva flow rates to be determined to ensure there

2 was a large enough volume $(\sim 1.5 \mathrm{~mL})$ collected for analysis. The familiarisation trial

3 was conducted in the same manner as the main trial. Participants cycled at $60 \%$

$4 \quad \dot{\mathrm{VO}}_{2 \max }$ for $2.5 \mathrm{~h}$ and then after a $5 \mathrm{~min}$ rest, completed a ride to fatigue at $75 \%$.

$5 \quad \dot{\mathrm{V}}{ }_{2 \max }$. Expired gas samples were collected into Douglas bags at 30, 90 and 114 min

6 to enable adjustments to be made to the work rate so that $60 \%$ of $\dot{\mathrm{VO}}_{2 \max }$ was

7 achieved throughout the 2.5 hours of cycling. Heart rate and RPE were also measured 8 every $15 \mathrm{~min}$.

\section{Experimental procedures}

11 Participants were requested to abstain from alcohol, caffeine and strenuous exercise 2 12 days prior to the trial. Participants arrived at the laboratory at $8: 30 \mathrm{~h}$ for the main trial 13 following an overnight fast $(10-12 \mathrm{~h})$ and were required to sit quietly for $5 \mathrm{~min}$ 14 before providing a saliva sample. The participants were then asked to empty their 15 bladders before body mass was measured wearing their shorts only. They then 16 performed $2.5 \mathrm{~h}$ cycling at $60 \% \dot{\mathrm{VO}_{2} \max }$ on a stationary cycle ergometer. Heart rate 17 and RPE were measured at 20 min intervals and expired gas was collected at $30 \mathrm{~min}$, 1890 min and 114 min of exercise for the analysis of $\dot{\mathrm{V}}_{2}$ using a Douglas bag.

19 Participants were given $200 \mathrm{~mL}$ of water every 20 min during exercise; in addition 20 they ingested $300 \mathrm{ml}$ of flavoured water immediately before the exercise began, and 21 again after $50 \mathrm{~min}$ and $110 \mathrm{~min}$ of exercise. Further saliva samples were collected 70 $22 \mathrm{~min}$ and $130 \mathrm{~min}$ of exercise. It was ensured that no fluid was consumed in the $10 \mathrm{~min}$ 23 prior to each saliva collection. Following completion of the $2.5 \mathrm{~h}$ cycling, the 
1 participants were allowed a 5 min rest before commencing the ride to exhaustion at

$275 \% \dot{\mathrm{VO}}_{2 \max }$ with no verbal encouragement and no information on time elapsed. The

3 time to exhaustion was $897 \pm 122 \mathrm{~s}$. A final saliva sample was obtained immediately

4 after completing the ride to exhaustion and body mass was measured. Mean

5 temperature and humidity in the laboratory during the trial were $23 \pm 0.5^{\circ} \mathrm{C}$ and $32 \pm$

$64 \%$ respectively.

8 Saliva collection

9 The saliva collections were made with the participants seated, leaning forward and

10 with their heads tilted down. They were instructed to swallow in order to empty the

11 mouth before a whole saliva sample was collected over a 3-min period into a pre-

12 weighed, $50 \mathrm{~mL}$ screw top sterile vial (Fisher Scientific, UK; UNSTIM). Care was

13 taken to allow saliva to dribble into the collecting tubes with making minimal

14 orofacial movement. At the end of the collection period subjects were instructed to

15 collect any saliva remaining in the mouth and expectorate it (Navazesh and

16 Christensen, 1982). The UNSTIM sample was immediately followed by $1 \mathrm{~min}$ of

17 chewing a commercially available sugar-free mint flavoured gum (1.8g portion, $11 \mathrm{kj}$,

$181.1 \mathrm{~g}$ carbohydrate) where participants were instructed to chew at a regular rate and

19 force (Proctor and Carpenter, 2001). Immediately after removing the gum the

20 participants provided a second saliva sample (STIM) as described above by dribbling

21 into a different tube for a further $1 \mathrm{~min}$. Samples were then stored at $-80^{\circ} \mathrm{C}$ until

22 analysis. 


\section{$1 \quad$ Saliva analysis}

2 Saliva volume was estimated by weighing to the nearest $\mathrm{mg}$ and the saliva density

3 was assumed to be $1.0 \mathrm{~g} \cdot \mathrm{mL}^{-1}$ (Cole and Eastoe, 1988). Saliva flow rate (mL.min ${ }^{-1}$ )

4 was determined by dividing the volume of saliva by the collection time. Salivary IgA

5 concentration was determined in duplicate by an enzyme-linked immunosorbent assay

6 (ELISA) and alpha-amylase activity was measured in duplicate using a

7 spectrophotometric method as described previously (Li and Gleeson, 2004).

8 Lysozyme (Biomedical Technologies Inc., USA) concentration following a 1000-fold

9 dilution of saliva with phosphate buffered saline (PBS), was analysed in duplicate

10 using a commercially available ELISA kit on a subset of twelve participants selected

11 at random, the number of which was determined upon findings from a previous study

12 (Allgrove et al., 2008). Osmolality was determined using a cryoscopic (freezing point 13 depression) osmometer (Osmomat 030, Gonotec, GbBH, Berlin, Germany) calibrated

14 with $300 \mathrm{mOsmol} . \mathrm{kg}^{-1} \mathrm{NaCl}$ solution. Secretion rates for the salivary analytes were

15 calculated by multiplying the concentration by the saliva flow rate. The intra-assay

16 coefficient of variation for the analytical methods used were $2.4 \%, 7.9 \%$ and $8.2 \%$ for

$17 \alpha$-amylase, IgA and lysozyme, respectively.

\section{Statistical analysis}

20 Data were checked for normality, homogeneity of variance and sphericity before

21 statistical analysis. A two-way ANOVA (2 treatments $\mathrm{x} 4$ sample times) with repeated

22 measures design was used to examine the salivary data. Data that were not normally

23 distributed were normalised with log transformation. Significant differences were 
1 assessed using Student's paired $t$-test with Holm-Bonferroni adjustments for multiple

2 comparisons. Differences in HR between the steady state exercise and time to

3 exhaustion ride were assessed using Student's paired $t$-tests. Data in text and tables

4 are presented as mean \pm SD. For clarity, data in figures are presented as mean \pm SEM.

$5 \quad$ Statistical significance was accepted at $P<0.05$.

6

$7 \quad$ Results

8 Physiological variables and RPE

9 Attainment of an average of $60 \% \dot{\mathrm{V}} \mathrm{O}_{2 \max }$ was achieved during the steady state

10 exercise; where mean $\dot{\mathrm{VO}}_{2}$ was $60.1 \pm 2.8 \% \dot{\mathrm{VO}}_{2 \max }$. Mean HR was $137 \pm 11$

11 beats. $\min ^{-1}$ and $174 \pm 9$ beats. $\min ^{-1}$ during the steady state exercise and the time to

12 exhaustion trial, respectively. Mean RPE measured during the steady state exercise

13 was $12 \pm 2$ and the post-exercise body mass loss was $0.53 \pm 0.10 \mathrm{~kg}(0.7 \pm 0.1 \%)$.

14

15 Salivary variables

16 Saliva flow rate

17 Saliva flow rate was significantly higher in STIM compared with UNSTIM

18 throughout the exercise protocol (main effect of treatment: $F_{1}, 23=177.10, P<$

19 0.001). Saliva flow rate decreased at $130 \mathrm{~min}$ of exercise and post-exhaustion in

20 STIM only (interaction: $F_{3}, 5_{6}=10.37, P<0.001$; Table 1 ).

21

$22 * * *$ Insert Table 1 near here*** 
2 Salivary lysozyme concentration

3 Salivary lysozyme concentration increased with exercise (main effect of time: $F_{3,33}=$

$4 \quad 23.97, P<0.001$ ), but there were no differences between methods (Table 1 ).

5

6 Salivary lysozyme secretion rate

7 Salivary lysozyme secretion rate increased with exercise (main effect of time: $F_{3,33}=$

$8 \quad 18.00, P<0.001$ ), and was significantly higher in STIM compared with UNSTIM

9 throughout the exercise protocol (main effect of treatment: $F_{1,11}=35.05, P<0.001$;

10 Figure 1).

11

$12 * * *$ Insert Figure 1 near here $* * *$

13

14 Salivary $\alpha$-amylase activity

15 Salivary $\alpha$-amylase activity increased with exercise (main effect of time: $F_{3,69}=$

$16107.77 ; P<0.001$ ), but there were no differences between methods (Table 1).

17

18 Salivary $\alpha$-amylase secretion rate

19 Salivary $\alpha$-amylase secretion rate increased with exercise (main effect of time: $F_{3}, 49$

$20=45.99 ; P<0.001)$ and was significantly higher in STIM compared with UNSTIM 
1 throughout the exercise protocol (main effect of treatment: $F_{1}, 23=166.85 ; P<$

2 0.001; Figure 2).

3

$4 \quad * * *$ Insert Figure 2 near here***

5

6

7 Salivary IgA concentration

8 Salivary IgA concentration increased with exercise duration (main effect of time: $F_{3}$,

$950=4.45 ; P<0.05)$, and was significantly higher in UNSTIM compared with STIM

10 throughout the exercise protocol (main effect of treatment: $F_{1,23}=44.84 ; P<0.001$;

11 Table 1).

12

13 
2 Salivary IgA secretion rate

3 Salivary IgA secretion rate increased post-exhaustion compared with baseline levels

4 (main effect of time: $F_{3,46}=9.81 ; P<0.001$ ) and was significantly higher in

5 UNSTIM compared with STIM (main effect of treatment: $F_{1,23}=5.15 ; P<0.05$;

$6 \quad$ Figure 3)

7

$8 \quad * * *$ Insert Figure 3 near here***

9

\section{Discussion}

13 The main findings of the study were 1) saliva flow rate decreased with exercise in

14 STIM only and was higher in STIM compared with UNSTIM 2) $\alpha$-amylase activity

15 and secretion rate and lysozyme concentration and secretion rate all increased with

16 exercise in both STIM and UNSTIM, and secretion rates were higher in STIM

17 compared with UNSTIM 3) s-IgA concentration and s-IgA secretion rate increased

18 post-exercise and were both lower in STIM compared with UNSTIM.

19

20 The results show a significant effect of stimulating saliva flow on saliva flow rate,

21 where it was 3-fold higher in STIM compared with UNSTIM and corroborates

22 previous findings (Hector and Linden, 1987). Saliva flow rate decreased following

23 exercise in the STIM trial only. Previous studies have attributed a reduction in flow 
1 rate during exercise to dehydration, although the small change in net mean body loss

2 of $(0.53 \pm 0.11 \mathrm{~kg} ; 0.7 \pm 0.1 \%)$, and lack of difference in the unstimulated trial

3 suggests that this had little impact (Walsh et al., 1999). It is possible that the

4 decreased parasympathetic nervous system activity during exercise and a removal of

5 vasodilatory influences (Proctor and Carpenter, 2007) may have limited the increase

6 in flow rate that occurs with chewing. Alternatively, the decline may be a result of

7 repetitive periods of chewing whereby the production of saliva may have become

8 temporarily exhausted over time (Proctor and Carpenter, 2001). Although saliva flow

9 rate in STIM was consistently higher than UNSTIM during the protocol, these

10 findings show that the saliva collection method employed during exercise can

11 differently affect the salivary flow response.

13 Stimulating saliva flow did not affect lysozyme concentration or $\alpha$-amylase activity.

14 Rudney (1989) also reported that salivary lysozyme was unaffected by the flow rate.

15 However, when these proteins were expressed as a secretion rate, significantly higher

16 values in STIM compared with UNSTIM were observed. Similar increases in parotid

$17 \alpha$-amylase activity secretion rate were reported by Proctor and Carpenter (2001)

18 following chewing, as would be expected given that $\alpha$-amylase is an enzyme that

19 functions to break down starch and glycogen to maltose in the oral cavity. In contrast

20 to these proteins, stimulating saliva flow resulted in a significantly lower s-IgA

21 concentration compared with UNSTIM throughout the exercise protocol, which has

22 been previously attributed to the increased saliva flow rate from chewing activating

23 the parotid gland functioning to dilute the saliva (Proctor and Carpenter, 2001).

24 However, when expressed as a secretion rate s-IgA levels were slightly lower in 
1 STIM compared with UNSTIM. These findings do not support other studies where

2 stimulating saliva flow increased the secretion rate of s-IgA at rest (Proctor and

3 Carpenter, 2001). However, Proctor and Carpenter (2001) stimulated saliva by

4 chewing on a piece of polythene tube whereas the current study administered a

5 commercially available flavoured chewing gum. The resulting differences between

6 masticatory stimulation only, from chewing the polythene tube, and gustatory and

7 masticatory stimulation combined when chewing flavoured gum, may explain some

8 of these differences. Despite a detrimental effect on the rate of s-IgA secretion during

9 exercise observed in STIM, levels remained above resting values, which may be

10 relevant in terms of oral immunity.

12 Significant increases in the salivary antimicrobial proteins were observed with

13 exercise which has been reported in previous studies (Blannin et al., 1998; Walsh et

14 al., 2004; Li and Gleeson, 2004; Sari-Sarraf et al., 2007; Allgrove et al., 2008; West et

15 al., 2010, Costa et al., 2012). $\alpha$-amylase and lysozyme levels increased consistently

16 during the exercise protocol, whereas S-IgA levels were elevated following the ride to

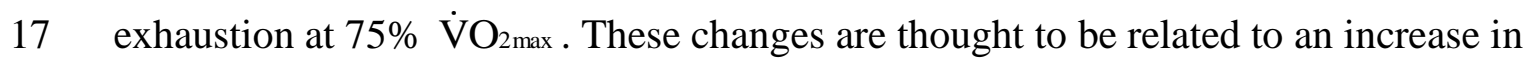

18 sympathetic nervous system (SNS) activity enhancing their transport and/or secretion

19 into saliva (Chatterton et al., 1996; Bishop et al., 2000; Walsh et al., 2002) and

20 suggest that there may be a threshold level of SNS activity to increase s-IgA secretion

21 during exercise, a finding that has been previously demonstrated in the rat model

22 (Carpenter et al., 2000). 
1 Differences in the secretion of the antimicrobial proteins with chewing may be related

2 to the way these proteins are stored and secreted into saliva. Lysozyme and $\alpha$-amylase

3 are stored in secretory granules which are released spontaneously upon autonomic

4 stimulation (Bosch et al., 2002). However, s-IgA is secreted onto mucosal surfaces

5 across epithelial cells via the polymeric immunoglobulin receptor, (Proctor and

6 Carpenter, 2001) which is activated by neuronal stimuli that may differ to other

7 salivary proteins. These findings show that the combination of masticatory and

8 gustatory stimuli through chewing flavoured gum activate the secretion of stored

9 salivary proteins into saliva (lysozyme and $\alpha$-amylase) but do not enhance the

10 (transport and subsequent secretion) of the receptor mediated secretion of s-IgA. A

11 further explanation may be related to the relative contributions of the different

12 salivary glands during unstimulated and stimulated saliva flow, since specific salivary

13 glands have been shown to be activated by some stimuli more than others (Noble,

14 2000). For example, mastication predominantly activates the parotid glands, which

15 produce large amounts of $\alpha$-amlyase. In contrast, strong taste stimuli activate the

16 submandibular and sublingual glands (from which lysozyme is mainly produced)

17 more than the parotid gland. Thus, the increase in $\alpha$-amylase and lysozyme by

18 chewing flavoured gum may be explained by the increase of salivary secretion from

19 these specific glands. The relative contribution of salivary glands for s-IgA secretion

20 is not clear. Crawford et al. (1975) reported s-IgA concentration to be four times

21 higher in the minor salivary glands than parotid glands although other data suggest a

22 low parotid s-IgA secretion rate is associated with high susceptibility to dental caries,

23 suggesting a greater role of the parotid gland in s-IgA secretion (Brandtzaeg, 1976).

24 These uncertainties make it difficult to relate the changes in s-IgA secretion in 
1 stimulated and unstimulated saliva flow to the stimulation of specific glands. From a

2 practical standpoint, these findings show that when investigating s-IgA, the saliva

3 flow rate must be considered.

5 A limitation of these findings is that it is not possible to distinguish whether the

6 differences between stimulated and unstimulated saliva flow were due to masticatory

7 or gustatory stimuli alone or in combination and future work might seek to address

8 this to determine which may have the most favourable response. In addition, the

9 practice of chewing during exercise may not be recommended in case of a risk of

10 choking, therefore administering a bitter isotonic beverage might be recommended as

11 a potential alternative. Nevertheless, the finding of an increase in the secretion rates of

12 lysozyme and $\alpha$-amylase with exercise which is further enhanced by stimulating

13 saliva flow suggest mechanisms by which resistance to oral infections might be

14 enhanced. These effects might have further benefits in immunocompromised

15 individuals where significant reductions in salivary antimicrobial proteins (i.e. below

16 basal levels) have been observed. At present, there are limited data to directly relate

17 the levels of these proteins in saliva to a reduced risk of upper respiratory symptoms

18 (Cunniffe et al., 2011) and given the present findings, this may be of interest.

\section{Perspective}

21 These findings show that prolonged exhaustive exercise in trained men can result in

22 increases in salivary antimicrobial proteins probably via an increase in SNS activity,

23 which may be regarded as beneficial to oral immune status. Moreover, a stimulated

24 saliva flow collection with exercise through chewing flavoured gum has a further

25 enhancing effect on $\alpha$-amylase and lysozyme secretion rate but has little effect on s- 
1 IgA secretion. The differences in these effects are likely related to the way that these

2 proteins are stored and secreted into saliva and/or by the activation of different

3 salivary glands by masticatory and gustatory stimuli. Understanding the effect of

4 exercise on salivary antimicrobial proteins and mechanisms or interventions that

5 might affect this response can enable us to employ measures to enhance immune

6 function which might reduce the incidence of URI.

\section{Acknowledgements}

9 We would like to acknowledge Alice Gallen, Sam Cheffins, and Ben Silver for their

10 help with the data collection. The authors are grateful for the funding support from

11 Wrigley.

13 References

Allgrove, JE, Gomes, E, Hough, J, Gleeson, M. Effect of exercise intensity on salivary antimicrobial proteins and markers of stress in active men. J Sports Sci 2008: 26: 653-61.

19 Allgrove JE, Geneen, L, Latif, S, Gleeson, M. Influence of a fed or fasted state on the 20 s-IgA response to prolonged cycling in active men and women. Int J Sport Nutr Exerc 21 Metab 2009: 19: 209-21.

23 Bishop, NC, Blannin, AK, Armstrong, E, Rickman, M, Gleeson, M. Carbohydrate and 24 fluid intake affect the saliva flow rate and IgA response to cycling. Med Sci Sports 25 Exerc $2000: 32: 2046-51$. 
2 Blannin, AK, Robson, PJ, Walsh, NP, Clark, AM, Glennon, L, Gleeson, M. The effect

3 of exercising to exhaustion at difficult intensities on saliva immunoglobulin A, protein

4 and electrolyte secretion. Int J Sports Med 1998: 19:547-52.

5

6 Bosch, JA, Ring, C, Geus, EJC, Veerman, ECI, Nieuw Amerogen, AV Stress and

7 secretory immunity. Int Rev Neurobiol 2002: 52: 213-53.

8

9 Brandtzaeg, P. Synthesis and secretion of secretory immunoglobulins: with special

10 reference to dental diseases. J Dent Res 1976: 55: C102-14.

11

12 Carpenter, GH, Proctor, GB, Andersen, LC, Zhang, XS, Garrett, JR. Immunoglobulin

13 A secretion into saliva during dual sympathetic and parasympathetic nerve stimulation

14 of rat submandibular glands. Exp Physiol 2000: 85: 281-6.

15

16 Chatterton, RT, Vogelsong, KM, Lu, YC, Ellmen, AB, Hudgens, GA. Salivary alpha-

17 amylase as a measure of endogenous adrenergic activity. Clin Physiol 1996: 1: 433-

1848.

19

20 Chicharro, JL, Lucia, A, Perez, M, Vaquero, A, Urena, R. Saliva composition and

21 Exercise. Sports Med 1998: 26: 17-27.

22

23 Cole, AS, Eastoe, JE. Biochemistry and Oral Biology. $2^{\text {nd }}$ ed. London: Wright: 1988

$24 \quad 476-7 \mathrm{p}$.

25 
1 Costa, RJ, Fortes, MB, Richardson, K, Blizon, JL and Walsh, NP. The effects of

2 postexercise feeding on saliva antimicrobial proteins. Int J Sport Nutr Exerc Metab.

$3 \quad 2012: 22: 184-91$

4

5 Crawford, JM, Taubman, MA Smith, DJ. Minor salivary glands as a major source of

6 secretory immunoglobulin A in the human oral cavity. Science 1975: 190: 1206-9.

8 Cunniffe B, Griffiths H, Proctor W, Davies B, Baker JS, Jones KP. Mucosal immunity

9 and illness incidence in elite rugby union players across a season. Med Sci Sports

10 Exerc 2011: 43: 388-97.

11

12 Davison G, Diment BC. Bovine colostrum supplementation attenuates the decrease of

13 salivary lysozyme and enhances the recovery of neutrophil function after prolonged

14 exercise. Br J Nutr 2010: 103: 1425-32.

15

16 Fahlman MM, Engels HJ. Mucosal IgA and URTI in American Collage Football

17 Players: A Year Longitudinal Study. Med Sci Sports Exerc 2005: 37: 374-380.

18

19 Fortes MB, Diment BC, Di Felice U, Walsh NP. Dehydration decreases saliva

20 antimicrobial proteins important for mucosal immunity. Appl Phys Nutri Metab 2012:

$21 \quad 37: 850-9$

22

23 Garrett JR. The proper role of nerves in salivary secretion: A review. J Dent Res 1987:

24 66: 387-97. 
1 Gleeson MW, McDonald A, Pyne DB, Cripps AW, Francis JL, Fricker PA, Clancy RL.

2 Salivary IgA levels and infection risk in elite swimmers. Med Sci Sports Exerc 1999:

$3 \quad 31: 67-73$.

4

5 Hector MP, Linden RW. The possible role of periodontal mechanoreceptors in the

6 control of parotid secretion in man. Q J Exp Physiol 1987: 72: 285-301.

7

8 Humphrey SP, Williamson RP. A review of saliva: normal composition, flow, and

9 function. J Prosthet Dent 2001: 85: 162-9.

10

11 Klentrou K, Cieslak, T, MacNeil, M, Vintinner, A, and Plyley, M. Effect of moderate exercise on salivary immunoglobulin A and infection risk in humans. Eur $\mathrm{J}$ of App Phys 2002: 87: 153-158.

Li TL, Gleeson M. The effect of single and repeated bouts of prolonged cycling and circadian variation on saliva flow rate, immunoglobulin A and $\alpha$-amylase responses. $\mathbf{J}$ Sports Sci 2004: 22: 1015-24. immunoglobulins following intense endurance exercise. Sports Training Med Rehab

21 1989: 1: 209-18.

23 McDowell SL, Chaloa K, Housh TJ, Tharp GD Johnson GO. The effect of exercise 24 intensity and duration on salivary immunoglobulin A. Eur J of Appl Physiol Occup 25 Physiol 1991: 63: 108-11. 
2 Navazesh, M, Christensen, CM. A comparison of whole resting and stimulated

3 salivary measurement procedures. J Dent Res 1982: 61: 1158-62

5 Neville V, Gleeson M. Folland, JP. Salivary IgA as a risk factor for upper respiratory

6 infections in elite professional athletes. Med Sci Sports Exerc 2008: 40: 1228-36.

7

8 Nieman D, Henson DA, Fagoaga OR, Utter AC, Vinci DM, Davis JM, Nehlsen-

9 Cannarella, SL. Change in salivary IgA following a competitive marathon race. Int J

10 Sports Med 2002: 23: 69-75.

11

12 Nehlsen-Cannaralla SL, Nieman DC, Fagoaga OR, Kelln WJ, Shannon M, Davis JM.

13 Saliva immunoglobulins in elite women rowers. Eur J Appl Physiol 2000: 81: 222-8.

15 Noble RE. Salivary alpha-amylase and lysozyme levels: a non-invasive technique for 16 measuring parotid vs. submandibular/sublingual gland activity. J Oral Sci 2000: 42: $17 \quad 83-6$.

18

19 Pedersen AM, Bardow A, Jensen SB, Nauntofte B. Saliva and gastrointestinal

20 functions of taste, mastication, swallowing and digestion. Oral Dis 2002: 8: 117-29.

21

22 Proctor GB Carpenter GH. Chewing stimulates secretion of human salivary secretory

23 immunoglobulin A. J Dental Res 2001: 80: 909-13.

24 
1 Proctor GB, Carpenter GH. Regulation of salivary gland function by autonomic nerves. Auton Neurosci. 2007: 133: 3-18.

3 Rudney JD. Relationships between human parotid saliva lysozyme, lactoferrin,

4 salivary peroxidase and sIgA in a large sample population. Arch Oral Biol 1989: 34:

$5 \quad 499-506$.

6

7 Sari-Sarraf V., Reilly T, Doran DA, Atkinson G. The effects of single and repeated

8 bouts of soccer-specific exercise on salivary IgA. Arch Oral Biol 2007: 52: 526-32.

9

10 Teeuw W, Bosch JA, Veerman EC, Amerongen AV. Neuroendocrine regulation of

11 salivary IgA synthesis and secretion: implications for oral health. Biol Chem 2004:

$12 \quad 385: 1137-46$.

13

14 Tomasi TB, Trudeau FB, Czerwinski D, Erredge S. Immune parameters in athletes

15 before and after strenuous exercise. J Clinl Immunol 1982: 2: 173-78.

16

17 West NP, Pyne DB, Kyd JM, Renshaw GM, Fricker PA, Cripps AW. The effect of

18 exercise on innate mucosal immunity. Br J Sports Med 2010: 44: 227-31.

19

20 Walsh NP, Bishop NC, Blackwell JB, Wierzbicki SG, Montague JC. Salivary IgA

21 response to prolonged exercise in a cold environment in trained cyclists. Med Sci

22 Sports Exerc 2002: 34: 1632-7.

23 
1 Walsh NP, Blannin AK, Clark AM, Cook L, Robson P J, Gleeson M. The effects of

2 high intensity intermittent exercise on saliva $\operatorname{IgA}$, total protein and [alpha]-amylase. $\mathrm{J}$

3 Sports Sci 1999: 17: 129-34.

4

5 Walsh NP, Laing SJ, Oliver SO, Montague JC, Walters R, Bilzon, JL. Saliva

6 parameters as potential indices of hydration status during acute dehydration. Med Sci

$7 \quad$ Sports Exerc 2004: 36: 1535-42.

8

9

10

11

12

13

14

15

16

17

18

19

20

21

22

23

24

25 


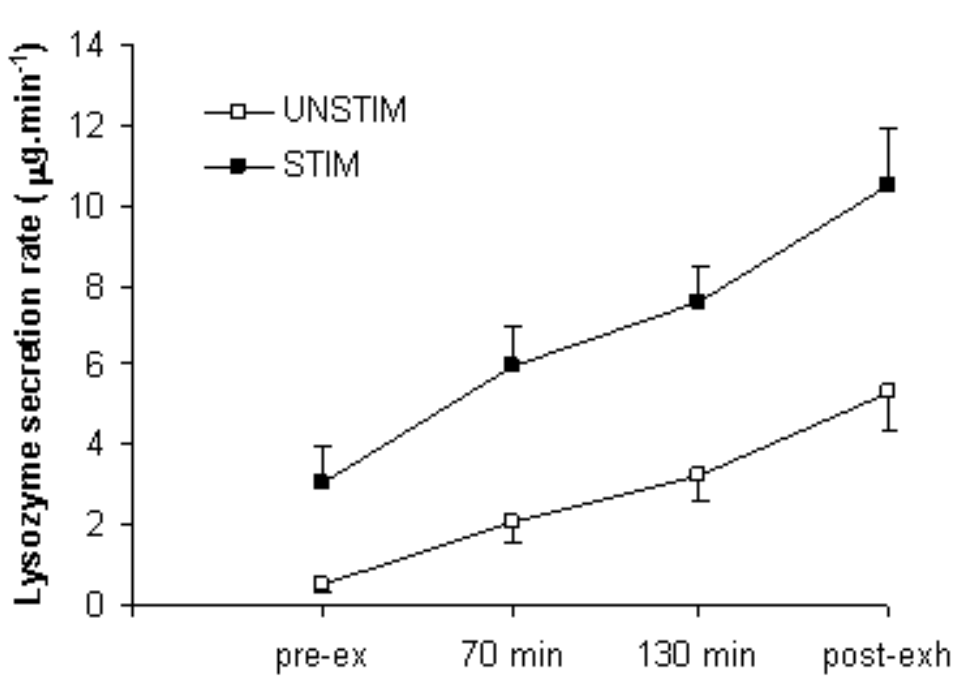

2 Figure 1. Changes in lysozyme secretion rate during exercise in unstimulated (UNSTIM) and 3 stimulated (STIM) flow conditions. Values are mean \pm SE

4

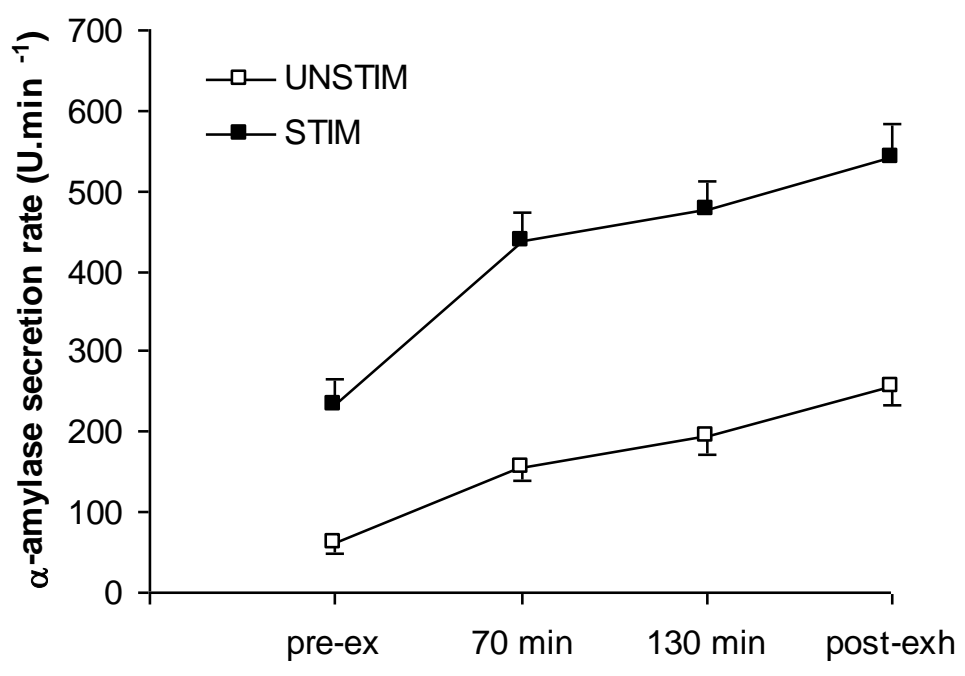

5

6 Figure 2. Changes in $\alpha$-amylase secretion during exercise in unstimulated (UNSTIM) and

$7 \quad$ stimulated (STIM) flow conditions. Values are mean \pm SE

8 


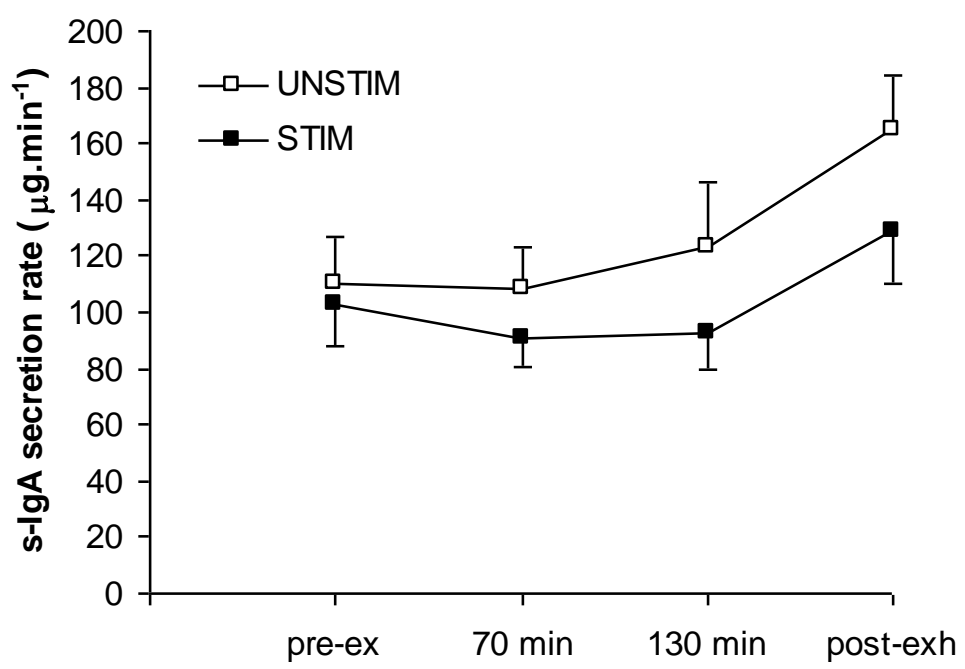

1

2 Figure 3. Changes in s-IgA secretion rate during exercise in unstimulated (UNSTIM) and

3 stimulated (STIM) flow conditions. Values are mean \pm SE

4

5

6 
1 Table 1. Changes in saliva flow rate, s-IgA concentration, lysozyme concentration and $\alpha$-amylase activity during exercise in unstimulated

2 (UNSTIM) and stimulated (STIM) flow conditions. Values are mean \pm SD

$$
\text { Pre-ex }
$$

$$
70 \mathrm{~min}
$$

$130 \mathrm{~min}$

Post-exh

Main effects $p$ values,

trial; time; trial x time

\section{Saliva flow rate}

$\left(\mathrm{ml} . \mathrm{min}^{-1}\right)$

$\begin{array}{lcccc}\text { UNSTIM } & 0.45(0.25) & 0.48(0.26) & 0.47(0.47) & 0.55(0.24) \\ \text { STIM } & 1.40(0.62) & 1.27(0.43) & 1.13(0.38)^{*} & 1.20(0.40)^{*}\end{array}$

S-IgA concentration

$\left(\mathrm{mg} . \mathrm{l}^{-1}\right)$

$\begin{array}{ll}\text { UNSTIM } & 291(250) \\ \text { STIM } & 76(42)\end{array}$

\section{Lysozyme concentration}

$\left(\mathrm{mg} . \mathrm{l}^{-1}\right)$

UNSTIM

$285(194)$

$80(41)$

$326(186)$

$111(79)$
$<0.001 ; 0.027 ;<0.001$

$>0.1 ;<0.001 ;>0.1$

$9.73(6.24)$ 
STIM

$2.08(2.01)$

$4.52(2.80)$

$6.49(2.63)$

$8.50(3.56)$

$\alpha$-amylase activity

$\left(\mathrm{U} \cdot \mathrm{ml}^{-1}\right)$

UNSTIM

$143(23)$

$171(22)$
$352(26)$

$349(22)$
$>0.1 ;<0.001 ;>0.1$

$418(28)$

$463(22)$

$427(17)$

$454(17)$

*Significantly different to pre-exercise $(\mathbf{P}<0.05)$ 